Clinical pharmacology

\title{
New hopes for the treatment of coronary heart disease
}

\section{Gilbert Thompson}

A RECENT 6-year surveyt of more than 350,000 middle-aged men in the United States confirms that both total mortality and death from coronary heart disease are strongly correlated with the concentration of cholesterol in the blood. Death rates rise steeply once serum cholesterol exceeds 6.5 millimoles per litre, and values above that level are found in 15 per cent of the population. In the United Kingdom, new epidemiological data ${ }^{2}$ indicate that there are twice as many men with this degree of hypercholesterolaemia. In most instances this problem can be managed by dietary means, but a significant minority of individuals will require drug therapy. A new agent that reduces the concentration of cholesterol in the blood is described by A.H. Underwood and colleagues on page 425 of this issue ${ }^{3}$.

The suggestion that hypercholesterolaemia causes coronary heart disease is confirmed by the atherogenetic effect of increased levels of low-density lipoprotein (LDL) cholesterol and the protective effect of high levels of high-density lipoprotein (HDL) cholesterol. Drugs that lower LDL and increase HDL are used to treat familial hypercholesterolaemia. People with this condition $(0.2$ per cent of the population of the United Kingdom) have a propensity to accelerated atherosclerosis and premature death from coronary heart disease. M. Brown and J. Goldstein discovered that this disorder represents a genetically determined defect of specific cell-surface receptors for LDL and have elucidated the structure and function of the receptors.

As illustrated in the figure, the LDL receptor provides a path of entry for exogenous cholesterol into the cell and reduces endogenous cholesterol synthesis through down-regulation of the ratelimiting enzyme $\beta$-hydroxy- $\beta$-methylglutaryl coenzyme A (HMG CoA) reductase $e^{4}$. The number of LDL receptors expressed and the activity of this enzyme in the cell have complementary roles in maintaining cholesterol homeostasis. This process is disturbed in familial hypercholesterolaemia where defective function of the receptors results in diminished uptake from plasma and decreased degradation of LDL, processes which normally take place mainly in the liver. The LDL receptor is a glycoprotein of relative molecular mass $160,000(160 \mathrm{~K})$, the gene for which is on chromosome 19, whereas HMG CoA reductase is a $97 \mathrm{~K}$ glycoprotein, the gene for which is on chromosome 5 (ref. 5). Several mutations of the gene encoding the receptor have been described ${ }^{6}$, any of which can give rise to familial hypercholesterolaemia, but no mutations of the gene encoding $\mathrm{HMG} \mathrm{CoA}$ reductase have been identified.

Hitherto the ability to stimulate hepatic LDL receptors has depended on the use of insoluble anion-exchange resins such as cholestyramine. These resins bind bile acids within the intestine and thus impair their re-absorption into the blood. To make good this loss, the rate of conversion of cholesterol to bile acids in the liver increases, the consequent need for ad-

\section{IMAGE \\ UNAVAILABLE \\ FOR \\ COPYRIGHT \\ REASONS}

A cultured fibroblast showing binding to receptor, endocytosis and lysosomal degradation of LDL, resulting in hydrolysis of protein to amino acids and of cholesteryl ester (linoleate) to free cholesterol. This leads to down-regulation of HMG CoA reductase and LDL receptors. Excess free cholesterol undergoes esterification to cholesteryl oleate by the enzyme acylcholesterylacyltransferase (ACAT). (Reproduced from ref. 11 with permission from M.S. Brown and J.L. Goldstein). ditional cholesterol being met partly by increased expression of LDL receptors and partly by a compensatory rise in cholesterol synthesis.

The LDL-lowering effects of cholestyramine can be markedly enhanced by concomitant administration of a new class of drugs that block cholesterol synthesis by competitively inhibiting $\mathrm{HMG} \mathrm{CoA}$ reductase. Like cholestyramine, these compounds promote receptor-mediated LDL catabolism but are much easier to take. They include mevinolin (lovastatin) and synvinolin, and look set to revolutionize the treatment of heterozygous familial hypercholesterolaemia ${ }^{7.8}$. Unfortunately homozygotes, with fewer functional LDL receptors, respond less well.

The new work of Underwood et al. ${ }^{3}$ in this issue is based on the well-known fact that thyroid hormones lower serum cholesterol. In attempts to use this effect therapeutically, avoiding undesirable side-effects by administering D-thyroxine instead of $\mathrm{L}$-thyroxine, even $\mathrm{D}$-thyroxine proved dangerous, causing cardiac arrythmias when given to patients with coronary heart disease, and its use has been largely discontinued. Underwood et al. ${ }^{3}$ have discovered a thyromimetic agent, SK\&F L-94901, which has significant cholesterol-lowering properties in animals. Their data suggest that this compound is equipotent to triiodothyranine in its effect on the liver but one thousandfold less active in its effect on the heart. Although its development is still at an early stage, the outlook seems promising. The mechanism of the cholesterollowering effect presumably involves enhancement of receptor-mediated LDL catabolism, which also occurs during treatment of hypothyroidism with $\mathrm{L}$ thyroxine $e^{9}$. The possibility that it stimulates selectively hepatic LDL receptors is intriguing but if, like thyroid hormones, SK\&F L-94901 also increases HMG CoA reductase activity ${ }^{10}$, it might be necessary to administer it with an $\mathrm{HMG} \mathrm{CoA}$ reductase inhibitor. Such a combination could be just what is needed if diet-resistant hypercholesterolaemia is to be treated as routinely and effectively as hypertension, as the evidence ${ }^{1}$ suggests it should. $\square$

1. Martin, M.J. et al. Lancet ii, 933 (1986).

2. Shaper, A.G. \& Pocock, S.J. Br. med. J. 291, 480 (1985)

3. Underwood, A.H. et al. Nature 324, 425 (1986).

4. Brown, M.S. \& Goldstein, J.L. Sci. Am. 251, 52 (1984)

5. Lindgren, V., Luskey, K.L., Russell, D.W. \& Francke, U. Proc natn. Acad. Sci. U.S. A. 82, 8567 (1985)

6. Tolleshaug, H., Hobgood, K.K., Brown, M.K. \& Goldstein, J.L. Cell 32, 941 (1983).

7. Thompson, G.R., Ford, J., Jenkinson, M. \& Trayner, I Q. J. Med. 60, 801 (1986)

8. Mol, M.J.T. et al. Lancet ii, 936 (1986).

9. Thompson, G.R. et al. Proc. natn. Acad. Sci. U.S.A. 78 2591 (1981).

10. Myant, N.B. The Biology of Cholesterol and Related Sterols (Heinemann, London, 1981).

11. Brown, M.S. \& Goldstein. J.L. Proc. natn. Acad. Sci. U.S.A. 76, 3330 (1979).

Gilbert Thompson is in the MRC Lipoprotein Team, Hammersmith Hospital, Du Cane Road, London W12 OHS, UK. 